\title{
Development and in Vitro Evaluation: Once-Daily Sustained Release Matrix Tablets of Propranolol
}

\author{
Rashmi Shivaji Tambare ${ }^{1 *}$, Minal Yashvant Chaudhari ${ }^{1}$, Suhas Marutirao Kakade ${ }^{2}$ \\ ${ }^{T}$ Shreeyash Institute of Pharmaceutical Education and Research, Maharashtra, India \\ ${ }^{2}$ Wockhardt Research Centre, Aurangabad, Maharashtra, India
}

\section{*Corresponding Author}

Rashmi Shivaji Tambare

\section{Article History}

Received: 04.03.2021

Accepted: 22.03.2021

Published: 26.03.2021

\begin{abstract}
The objective of the present study was to develop once-daily sustained-release matrix tablets of propranolol used in the treatment of hypertension, angina pectoris, and many other cardiovascular disorders. The constrained mixture experimental design was used to prepare systematic model formulations, which were composed of Eudragit RSPO and different viscosity grades of HPMC (Methocel E50 and Methocel K15M CR). The matrix tablets were prepared by direct compression process. The prepared tablets were evaluated for various physico-chemical parameters. In vitro release profile was check for $24 \mathrm{hrs}$ to evaluate the SR matrix tablet of propranolol. Increase in Eudragit RSPO and HPMC concentrations or increase in viscosity grades of HPMC polymers (Methocel E50 and Methocel K15M CR) resulted in a significant decrease in propranolol release. Administration of propranolol in a sustained release dosage would be more desirable for antihypertensive effects by maintaining the plasma concentrations of the drug well above the therapeutic concentration. From in vitro dissolution profile, Batch F4 was prepared with blend of Eudragit RSPO $(80 \mathrm{mg})$, Methocel E50 $(60 \mathrm{mg})$ and Methocel K15M CR $(80 \mathrm{mg})$ where drug release was about $98.11 \%$
\end{abstract}

Keywords: Sustained release, Propranolol, Eudragit RSPO, HPMC, Methocel E50, Methocel.

\section{INTRODUCTION}

Among various dosage forms, matrix tablets are widely accepted for oral sustained release (SR) as they are simple and easy formulate. Matrix system is the release system, which prolongs and controls the release of drug that is dissolved or dispersed [1]. In fact, matrix is defined as a well composite of one or more drugs with a gelling agent i.e. hydrophilic polymer. Past research therefore acknowledged various hydrophilic natural gums like agar, konjac, guar gum, chitosan, sodium alginate and locust bean gum in alone or in combination [2].

The design of sustained release delivery system is subject to several variables of considerable importance. Among these, route of drug delivery, the type of delivery system, the disease being treated, the patient, length of therapy and the properties of the drug. The drug should be stable in the gastro-intestinal tract as the sustained release systems release their contents over entire length of gastrointestinal tract. Therefore, drugs degraded by the acid environment of the stomach or degraded by the basic environment of intestine are unsuitable for formulation into sustained release dosage forms.

The matrix tablet by direct compression has attracted much attention due to its technological simplicity in comparison with other controlled release systems. It required fewer unit operations, less machinery, reduced number of personnel and processing time, increased product stability and production rate [3]. HPMC, a semi synthetic derivative of cellulose, is a swellable and hydrophilic polymer. Some research groups have worked on the usage of swellable HPMC as the retarding polymer to sustain the release of different drugs [4-5]. It is very suitable to use as a retardant material in controlled release matrix tablets, as it is nontoxic and easy to handle [6]. Matrix tablets prepared using HPMC on contact

Copyright (C) 2021 The Author(s): This is an open-access article distributed under the terms of the Creative Commons Attribution 4.0 International License (CC BY-NC 4.0) which permits unrestricted use, distribution, and reproduction in any medium for non-commercial use provided the original author and source are credited. 
with aqueous fluids gets hydrated to form a viscous gel layer through which drug will be released bydiffusion and/or by erosion of the matrix [7].

Propranolol, a non-selective beta adrenergic blocking agent, has been widely used in the treatment of hypertension, angina pectoris, and many other cardiovascular disorders. It is highly lipophilic and is almost completely absorbed after oral administration. However, its bioavailability is very limited (30\%) due to the hepatic first-pass effect. Its elimination half-life is also relatively short (about 2-6 h) [8-12]. Therefore, it was chosen as a model drug for preparation of the once-daily extended-release dosage form.

\section{Materials AND Methods}

Propranolol was obtained as gift sample from Alkem Pharma Ltd., HPMC (Methocel E50, Methocel K15M CR) was a gift sample received from Colorcon Asia Pvt. Ltd., Avicel PH 102 was gift sample from Signet Chemical Corporation. Eudragit RSPO was procured from Evonik Degussa India Pvt. Ltd. All chemicals and reagents used were of analytical grade.

\section{Preparation of Tablets}

Tablets were prepared by direct compression process. The composition of each tablet is shown in Table 1 . Different batches of tablets, F1 to F8 were prepared by varying the concentration of Eudragit RSPO (15-20\%), HPMC polymer Methocel E50 (15-20\%) and Methocel K15M CR (10-20\%). The drug was passed through 40\# sieve. Eudragit RSPO, Methocel E50 and Methocel K15M CR were passed through 30\# sieve. All other ingredients were passed through 40\# sieve. All ingredients were mixed for 15-20 min. After mixing, Magnesium stearate (60\# sieve), was added during blending. During blending total mass was taken in a laboratory designed small drum blender machine for about 30 min. Particular attention was given to ensure thorough mixing and phase homogenization. Compression was done on Rimiek type 10-station compression machine, Germany, using $10 \mathrm{~mm}$ punch.

\section{Evaluation of Granules}

Granules were evaluated for the flow parameters such as angle of repose Tap density, Hausner ratio and Carr's index as given Table 2 .

\section{Angle of repose}

The angle of repose of powder was determined by the funnel method. The accurately weighed powder was taken in a funnel. The height (h) of the funnel was adjusted in such a way that the tip of the funnel just touches the apex of the heap of the powder. The powder was allowed to flow through funnel freely on to the surface. The diameter of the powder cone was measured and angle of repose was calculated using the following equation [13, 14].

$$
\begin{gathered}
\tan \theta=\mathrm{h} / \mathrm{r} \\
\text { Therefore } \theta=\tan \mathrm{h} / \mathrm{r}
\end{gathered}
$$

Where $\theta=$ angle of repose, $\mathrm{h}=$ height of the pile, $\mathrm{r}=$ radius of the pile base

\section{Bulk Density}

Apparent bulk density $(\mathrm{Pb})$ was determined by pouring blend into a graduated cylinder. The bulk volume $(\mathrm{Vb})$ and weight of the powder (M) was determined. The bulk density was calculated by using the following formula [15].

$$
\mathrm{Pb}=\mathrm{M} / \mathrm{Vb}
$$

\section{Tapped Density}

The measuring cylinder containing known mass of blend was tapped for a fixed time. The minimum volume $(\mathrm{Vt})$ occupied in the cylinder and weight $(\mathrm{M})$ of the blend as measured. The tapped density (Pt) was calculated using the formula [15].

$$
\mathrm{Pt}=\mathrm{M} / \mathrm{Vt}
$$

\section{Carr's compressibility index}

The simplex way of measurement of the free flow of blend is compressibility, an indication of the ease with which a material can be induced to flow is given by compressibility index of the granules was determined by Carr's compressibility index (I) which is calculated by using the following formula [15].

$$
\mathrm{I}=\{(\mathrm{Vb}-\mathrm{Vt}) / \mathrm{Vb}\} \mathrm{X} 100
$$




\section{Hausner ratio}

Hausner ratio is an indirect index of ease of blend flow. It is calculated by the following formula [15].

$$
\text { Hausner ratio }=\mathrm{Pt} / \mathrm{Pb}
$$

Lower hausner ratio $(<1.25)$ indicate better flow properties than higher ones $(>1.25)$.

\section{Evaluation of tablets}

Uniformity of weight

Twenty tablets were taken and their weight was determined individually and collectively on a digital weighing balance. The average weight of one tablet was determined from the collective weight [16].

\section{Thickness}

The thickness of the tablet was measured by using digital venire caliper, twenty tablets from each batch were randomly selected and thickness was measured [16].

\section{Hardness}

Hardness was determined by taking six tablets from each formulation, using a Monsanto Hardness Tester [16].

\section{Friability}

The friability of sample of six tablets ware measured using a Roche Fribilator. Six pre-weighed tablets were rotated at $25 \mathrm{rpm}$ for 4 minutes. The tablets were then reweighed after removal of fine's using 60 mesh screen and the percentage of weight loss was calculated [16].

$$
\% \text { Friability }=(\text { Loss in weight } / \text { Initial weight }) \times 100
$$

\section{Drug content uniformity}

Twenty tablets were weighed and powdered. An amount of the powder equivalent to $100 \mathrm{mg}$ of Propranolol was dissolved in $100 \mathrm{ml}$ of pH 7.4 phosphate buffer, filtered, diluted suitably and analyzed for drug content at $290 \mathrm{~nm}$ using UV-Visible spectrophotometer (UV 1601- Shimadzu, Japan) [16].

\section{Dissolution studies}

In vitro drug release studies for the prepared matrix tablets were conducted for a period of 24 hrs using USP XXII apparatus-I $37 \pm 0.5^{\circ} \mathrm{C}$ and at $100 \mathrm{rpm}$ speed, the in vitro release study was performed in $0.1 \mathrm{~N} \mathrm{HCL} \mathrm{pH} 1.2$ for $2 \mathrm{hrs}$ and in phosphate buffer $\mathrm{pH} 7.4$ up to $24 \mathrm{hrs}$. At every interval $5 \mathrm{ml}$ of sample was withdrawn from the dissolution medium and replaced with fresh medium to maintain the volume constant. After filtration and appropriate dilution, the sample solutions were analyzed at $290 \mathrm{~nm}$ for propranolol by a UV-Visible spectrophotometer [16].

\section{Release kinetics}

Different kinetic models (zero-order, first-order, Higuchi's, Korsmeyer's and Hixson Crowell) were applied to interpret the release profile (the order and mechanism of propranolol release) from matrix system. To study the mechanism of drug release from the matrix tablets, the release data were fitted to zero-order, first-order, and Higuchi equation. However, two factors diminish the applicability of Higuchi's equation to matrix systems. This model fails to allow the influence of swelling of the matrix (upon hydration) and gradual erosion of the matrix. Therefore, the dissolution data were also fitted according to the well-known exponential equation (Korsmeyer equation), Eq. (1), which is often used to describe the drug release behavior from polymeric systems.

$$
\log (\mathrm{Mt} / \mathrm{Mf})=\log \mathrm{k}+\mathrm{n} \log \mathrm{t}
$$

Where, Mt is the amount of drug release at time $\mathrm{t}$; $\mathrm{Mf}$ is the amount of drug release after infinite time; $\mathrm{k}$ is a release rate constant incorporating structural and geometric characteristics of the tablet; and $\mathrm{n}$ is the diffusional exponent indicative of the mechanism of drug release. Applied this equation to evaluate the drug release mechanism [17]. To clarify the release exponent for different batches of matrix tablets, the log value of percentage drug dissolved was plotted against $\log$ time for each batch according to the equation 1 . A value of $n=0.45$ indicates Fickian (case I) release; $>0.45$ but $<0.89$ for non-Fickian (anomalous) release; and $>0.89$ indicates super case II type of release. Case II generally refers to the erosion of the polymeric chain and anomalous transport (non- Fickian) refers to a combination of both diffusion and erosion controlled-drug release [18].

The Hixson - Crowell cube root equation is:

$$
\mathrm{M} 1 / 3=\mathrm{Mo}^{1 / 3}-\mathrm{Kct} \text {---------------- (2) }
$$


Where, $\mathrm{Kc}$ is the cube root dissolution rate constant. Cube roots of percent releases (Cube root of initial drug load minus cube root of \% drug remaining) are plotted against time (hour) to demonstrate the Hixson Crowell plot. Mean dissolution time (MDT) was calculated from dissolution data using the following equation [19].

$$
\operatorname{MDT}=(n / n+1) K^{-1 / n}
$$

\section{Statistical Analysis}

A one way analysis of variance (ANOVA) was used to analyze the dissolution data obtained for each batch of formulation to compare the drug release rate and comparison of mean dissolution time (MDT) of all formulations. A confidence limit of $P<0.05$ was fixed and the theoretical calculated values of $F$ (Fcrit and Fcal) were compared for the interpretation of results. ANOVA was determined using SPSS software (Version 12, SPSS Inc., USA) [20].

\section{RESULTS AND DISCUSSION}

Propranolol with all evident advantages proved to be a suitable candidate for development of a sustained-release dosage form. In present study, HPMC E50 and HPMC K15M CR, which were used in hydrophilic matrix drug delivery systems, have been employed to formulate sustained-release tablets of propranolol but alone it was not gives a good result so it was used in combination with hydrophobic polymer like Eudragit RSPO.

The Pre formulation studies or Micromeritic Characterization of powder blend evaluated were found to be Angle of repose range from $27.16 \pm 1.43$ to $28.91 \pm 0.21$, Bulk density range from $0.320 \pm 0.051$ to $0.343 \pm 0.041$, Tapped density $0.389 \pm 0.019$ to $0.419 \pm 0.011$ and Carr's index range from $17.51 \pm 1.29$ to $18.51 \pm 1.16$ respectively, which indicate good flow property are shown in (Table No. 2).

The prepared sustained release tablets were evaluated for thickness, weight variation, hardness, friability, drug content and In vitro drug dissolution studies. All the studies were performed in triplicate, and results are expressed as mean \pm SD are shown in (Table No. 3 ).

The Average weight of the tablets were ranged from $400.3 \pm 1.2 \mathrm{mg}$ to $400.0 \pm 1.1 \mathrm{mg}$, Thickness were ranged from $2.9 \pm 0.06 \mathrm{~mm}$ to $3.2 \pm 0.26 \mathrm{~mm}$, Hardness were ranged from $5.8 \pm 0.20 \mathrm{~kg} / \mathrm{cm}^{2}$ to $6.1 \pm 0.15 \mathrm{~kg} / \mathrm{cm}^{2}$, The percentage friability were ranged from $0.077 \pm 0.001 \%$ to $0.087 \pm 0.002 \%$ and drug content of different batches ranged from $98.38 \pm 0.46 \%$ to $99.79 \pm 0.34 \%$ respectively, which is in acceptable criteria in tablet formulation.

\section{In-Vitro dissolution studies}

The result of the dissolution study indicating that F1, F2, F3 and F4 released 20.54, 20.23, 30.31 and 11.33 of propranolol at the end of $2 \mathrm{hrs}$ and 87.11, 90.23, 95.33 and 98.11 at end of $24 \mathrm{hrs}$ respectively. Formulation F5, F6, F7 and F8 released 21.21, 35.12, 18.45 and 14.56 at the end of $2 \mathrm{hrs}$ and $96.16,95.11,90.56$ and 93.12 at the end of $24 \mathrm{hrs}$. The released rate of propranolol in formulation F4 was comparatively higher than other formulations the concentration of polymers, Eudragit RSPO, HPMC (Methocel E50) and HPMC (K15M CR) in F4 were 20\%, 15\% and $20 \%$ w/w. This polymer concentration has been well known to retard the drug release by swelling in aqueous media. A polymer's ability to retard the drug release rate is related to its viscosity. The hydration rate of HPMC depends on the nature of the substituents like hydroxypropyl group content. Hence, HPMC (Methocel E50 and Methocel K15M CR) was used because it forms a strong viscous gel in contact with aqueous media, which may be useful in controlled delivery of drug [21]. The effect of polymer concentrations on drug release from matrix tablets is shown in Fig.1. It can be seen that by increase the polymer concentration combination $15 \%$ and $20 \%$, the rate of drug release from the matrix tablet decreases dramatically. The formulations containing relatively higher polymer content shows less initial drug release due to the unavailability of drug molecules at the surface of matrix tablets. Further, by increasing the concentration of polymer in the tablets formulation, a point will be reached where the pores or channels formed by the drug particles within the polymer matrix were diminished. i.e., the diffusion of drug molecules from the channels of the matrix was disturbed by the increased concentration of polymer. In addition, lactose causes a decreased tortuosity of the path of the drug due to its preferential solubility than Methocel K15M CR and Methocel E50, by its swelling effect, additionally weakened the integrity of the matrix [19]. In other words, increased polymer concentration affects the drug leaching and diffusion process from the matrix, by making it less porous and slower drug release rate occurs. Further, the drug release from combination of higher HPMC viscosity grade (Methocel K15M) and lower viscosity grade (Methocel E50). i.e. the drug release slower and polymer proportion in the matrix tablet.

\section{Release kinetics}

The data obtained from in vitro dissolution studies were fitted in different models viz. zero order, first order, Higuchi and Korsemeyer- Peppas equation, the results were shown in Table 3. It was also observed that highest correlation was found for Zero order profile $(\mathrm{R} 2>0.99)$, which indicates the drug release via diffusion mechanism from 
hydrophilic matrices. To confirm the exact mechanism of drug release from these tablets, the data were fitted according to Korsemeyer- Peppas equation. A value of $n$ for all matrices studied here was ranged between 0.97 to 0.99 , indicating an anomalous behavior corresponding to swelling, diffusion and erosion mechanism.

From the study, it is possible to conclude that the proposed tablet formulations were suitable for direct compression method using different viscosity grades of HPMC showed excellent time-delayed release of the drug. An optimal lag period in both acidic and basic environments, due to the initial swelling of polymers, followed by complete drug release in a controlled manner could be obtained owing mainly to diffusion through the swollen polymer and in part to the slow erosion. Thus, the delayed-onset extended-release system of propranolol may be beneficial for alleviating the symptoms of hypertension and related cardiovascular diseases. The results are not only encouraging but they also promise effective management of such diseases through this novel approach after suitable trials in animal models and human beings.

Table-1: Composition of sustained release matrix tablets of propranolol.

\begin{tabular}{|c|c|c|c|c|c|c|c|c|}
\hline \multirow{2}{*}{$\begin{array}{l}\text { Formulation } \\
\text { Code }\end{array}$} & \multicolumn{8}{|c|}{ Ingredients per tablet (mg) } \\
\hline & Propranolol & $\begin{array}{c}\text { Eudragit } \\
\text { RSPO } \\
(15-20 \%)\end{array}$ & $\begin{array}{c}\text { Methocel } \\
\text { E50 } \\
(15-20 \%)\end{array}$ & $\begin{array}{l}\text { Methocel } \\
\text { K15M CR } \\
(10-20 \%)\end{array}$ & Lactose & $\begin{array}{c}\text { Avicel } \\
\text { PH } 102\end{array}$ & $\begin{array}{c}\text { Magnesium } \\
\text { stearate }\end{array}$ & Talc \\
\hline F1 & 100 & 60 & 60 & 40 & 91 & 45 & 2 & 2 \\
\hline $\mathrm{F} 2$ & 100 & 60 & 60 & 80 & 51 & 45 & 2 & 2 \\
\hline F3 & 100 & 80 & 60 & 40 & 71 & 45 & 2 & 2 \\
\hline $\mathrm{F} 4$ & 100 & 80 & 60 & 80 & 31 & 45 & 2 & 2 \\
\hline F5 & 100 & 60 & 80 & 40 & 71 & 45 & 2 & 2 \\
\hline F6 & 100 & 60 & 80 & 80 & 31 & 45 & 2 & 2 \\
\hline F7 & 100 & 80 & 80 & 40 & 51 & 45 & 2 & 2 \\
\hline F8 & 100 & 80 & 80 & 80 & 11 & 45 & 2 & 2 \\
\hline
\end{tabular}

Table-2: Micrometrics properties of sustained release matrix tablets of propranolol

\begin{tabular}{|l|c|c|c|c|}
\hline Formulation Code & $\begin{array}{c}\text { Angle of repose } \\
\boldsymbol{\theta} \pm \mathbf{S D}\end{array}$ & $\begin{array}{l}\text { Bulk density } \\
(\mathbf{g m} / \mathbf{m l}) \pm \mathbf{S D}\end{array}$ & $\begin{array}{c}\text { Tapped density } \\
(\mathbf{g m} / \mathbf{m l}) \pm \text { SD }\end{array}$ & $\begin{array}{l}\text { Carr's index } \\
(\boldsymbol{\%}) \pm \text { SD }\end{array}$ \\
\hline F1 & $27.36 \pm 0.31$ & $0.339 \pm 0.024$ & $0.411 \pm 0.015$ & $17.51 \pm 1.29$ \\
\hline F2 & $28.38 \pm 0.59$ & $0.343 \pm 0.041$ & $0.419 \pm 0.011$ & $18.40 \pm 1.11$ \\
\hline F3 & $28.49 \pm 0.26$ & $0.330 \pm 0.029$ & $0.405 \pm 0.026$ & $18.51 \pm 1.16$ \\
\hline F4 & $28.91 \pm 0.21$ & $0.334 \pm 0.024$ & $0.409 \pm 0.036$ & $18.33 \pm 1.05$ \\
\hline F5 & $28.46 \pm 0.55$ & $0.320 \pm 0.051$ & $0.389 \pm 0.019$ & $17.73 \pm 1.32$ \\
\hline F6 & $27.16 \pm 1.43$ & $0.331 \pm 0.042$ & $0.402 \pm 0.023$ & $17.66 \pm 1.29$ \\
\hline F7 & $28.65 \pm 1.12$ & $0.326 \pm 0.026$ & $0.399 \pm 0.015$ & $18.29 \pm 0.91$ \\
\hline F8 & $28.48 \pm 0.54$ & $0.336 \pm 0.028$ & $0.412 \pm 0.031$ & $18.44 \pm 1.24$ \\
\hline
\end{tabular}

Table-3: Post compressional parameters of sustained release matrix tablets of propranolol

\begin{tabular}{|l|c|c|c|c|c|}
\hline $\begin{array}{l}\text { Formulation } \\
\text { Code }\end{array}$ & $\begin{array}{c}\text { Average Weight } \\
(\mathbf{m g})\end{array}$ & $\begin{array}{c}\text { Thickness } \\
(\mathbf{m m})\end{array}$ & $\begin{array}{c}\text { Hardness } \\
\left(\mathbf{k g} / \mathbf{c m}^{\mathbf{2}}\right)\end{array}$ & $\begin{array}{c}\text { Friability } \\
(\mathbf{\%})\end{array}$ & $\begin{array}{c}\text { Drug content } \\
(\mathbf{\%})\end{array}$ \\
\hline F1 & $400.3 \pm 1.2$ & $3.1 \pm 0.15$ & $6.0 \pm 0.10$ & $0.084 \pm 0.002$ & $99.76 \pm 0.10$ \\
\hline F2 & $400.0 \pm 1.1$ & $3.0 \pm 0.11$ & $5.8 \pm 0.35$ & $0.086 \pm 0.001$ & $99.16 \pm 0.53$ \\
\hline F3 & $400.2 \pm 1.1$ & $3.2 \pm 0.26$ & $6.0 \pm 0.15$ & $0.083 \pm 0.002$ & $98.41 \pm 0.21$ \\
\hline F4 & $400.1 \pm 1.1$ & $3.1 \pm 0.15$ & $5.9 \pm 0.25$ & $0.077 \pm 0.001$ & $99.49 \pm 0.16$ \\
\hline F5 & $400.3 \pm 1.0$ & $3.0 \pm 0.26$ & $6.0 \pm 0.10$ & $0.081 \pm 0.002$ & $99.79 \pm 0.34$ \\
\hline F6 & $400.2 \pm 1.2$ & $3.1 \pm 0.13$ & $6.1 \pm 0.15$ & $0.083 \pm 0.001$ & $98.38 \pm 0.46$ \\
\hline F7 & $400.0 \pm 1.2$ & $3.2 \pm 0.06$ & $5.8 \pm 0.25$ & $0.087 \pm 0.002$ & $98.96 \pm 0.10$ \\
\hline F8 & $400.1 \pm 1.1$ & $2.9 \pm 0.06$ & $5.8 \pm 0.20$ & $0.085 \pm 0.002$ & $99.53 \pm 0.15$ \\
\hline
\end{tabular}

Table-4: Correlation coefficients according to different kinetic equations used for describing propranolol release behavior

\begin{tabular}{|c|c|c|c|c|c|c|c|c|c|c|}
\hline \multirow[t]{2}{*}{ Formulation Code } & \multicolumn{2}{|c|}{ Zero order } & \multicolumn{2}{|c|}{ First order } & \multicolumn{2}{|c|}{ Higuchi } & \multicolumn{2}{|c|}{ Korsmeyer } & \multicolumn{2}{|c|}{ Hixson Crowell } \\
\hline & $\mathbf{R}^{2}$ & $K_{0}\left(\% h^{-1}\right)$ & $\mathbf{R}^{2}$ & $K_{1}\left(\% h^{-1}\right)$ & $\mathbf{R}^{2}$ & $K_{h}\left(\% h^{-0.5}\right)$ & $\mathbf{R}^{2}$ & $\mathbf{n}$ & $\mathbf{R}^{2}$ & $K_{c}\left(\% h^{-1}\right)$ \\
\hline F1 & 0.815 & 9.323 & 0.981 & -0.098 & 0.991 & 29.780 & 0.991 & 0.445 & 0.948 & 0.253 \\
\hline $\mathrm{F} 2$ & 0.909 & 8.102 & 0.932 & -0.056 & 0.989 & 25.821 & 0.997 & 0.459 & 0.963 & 0.196 \\
\hline F3 & 0.933 & 7.395 & 0.971 & -0.069 & 0.992 & 23.365 & 0.972 & 0.476 & 0.950 & 0.179 \\
\hline $\mathrm{F} 4$ & 0.851 & 9.192 & 0.979 & -0.096 & 0.996 & 29.091 & 0.989 & 0.453 & 0.967 & 0.246 \\
\hline F5 & 0.906 & 7.943 & 0.965 & -0.055 & 0.987 & 25.493 & 0.986 & 0.497 & 0.958 & 0.191 \\
\hline F6 & 0.929 & 8.142 & 0.943 & -0.064 & 0.993 & 22.536 & 0.984 & 0.534 & 0.964 & 0.175 \\
\hline F7 & 0.921 & 7.421 & 0.966 & -0.058 & 0.989 & 23.440 & 0.979 & 0.493 & 0.959 & 0.169 \\
\hline F8 & 0.927 & 7.442 & 0.974 & -0.062 & 0.986 & 25.631 & 0.988 & 0.530 & 0.957 & 0.164 \\
\hline
\end{tabular}


R2-Correlation coefficients, $\mathrm{K}_{0}, \mathrm{~K}_{1}, \mathrm{~K}_{\mathrm{h}}, \mathrm{K}_{\mathrm{c}}$ Release rate constant for zero order, first order, Higuchi, and Hixson Crowell release equation, respectively, $\mathrm{n}$, diffusional exponent, indicative of release mechanism in Korsmeyer equation. All formulations except F1 and F4, (Fickian release) followed Non-Fickian (Anomalous) release

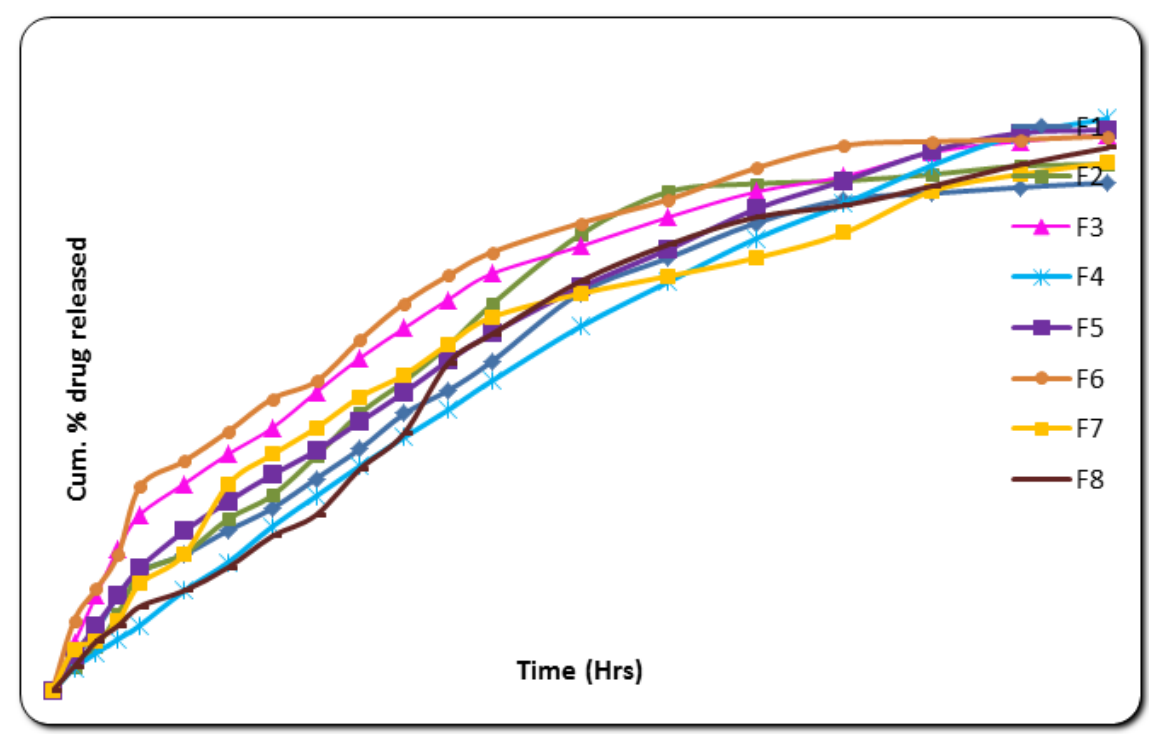

Fig-1: Comparative release profile of sustained release matrix tablets of propranolol

\section{ACKNOWLEDGMENTS}

The authors wish to thank Shreeyash Institute of Pharmaceutical Education and Research, Maharashtra, India for providing constant support and enthusiasm to complete this work.

\section{Competing Interest}

The authors declare that they have no competing interests.

\section{REFERENCES}

1. Chien, Y.W. (2005). Novel drug delivery system. 2nd ed. New York: Marcel Decker Inc; 1-3.

2. Derle, D. V., Kasiwal, N. H., \& Chavan, N. (2008). Development and comparative evaluation of xanthan gum and guar gum based sustained release matrix tablets of tizanidine hydrochloride. Indian drugs, 45(6), 485-9.

3. Reddy, K. R., Mutalik, S., \& Reddy, S. (2003). Once-daily sustained-release matrix tablets of nicorandil: formulation and in vitro evaluation. AAPS pharmscitech, 4(4), 480-488.

4. Bravo, S. A., Lamas, M. C., \& Salomon, C. J. (2004). Swellable matrices for the controlled-release of diclofenac sodium: Formulation and in vitro studies. Pharmaceutical development and technology, 9(1), 75-83.

5. Heng, P. W. S., Chan, L. W., Easterbrook, M. G., \& Li, X. (2001). Investigation of the influence of mean HPMC particle size and number of polymer particles on the release of aspirin from swellable hydrophilic matrix tablets. Journal of Controlled Release, 76(1-2), 39-49.

6. Lee, B. J., Ryu, S. G., \& Cui, J. H. (1999). Formulation and release characteristics of hydroxypropyl methylcellulose matrix tablet containing melatonin. Drug development and industrial pharmacy, 25(4), 493-501.

7. Katzhendler, I., Mäder, K., \& Friedman, M. (2000). Structure and hydration properties of hydroxypropyl methylcellulose matrices containing naproxen and naproxen sodium. International journal of pharmaceutics, 200(2), 161-179.

8. Rekhi, G. S., Porter, S. C., \& Jambhekar, S. S. (1995). Factors affecting the release of propranolol hydrochloride from beads coated with aqueous polymeric dispersions. Drug development and industrial pharmacy, 21(6), 709-729.

9. Taylan, B., Capan, Y., Güven, O., Kes, S., \& Hincal, A. A. (1996). Design and evaluation of sustained-release and buccal adhesive propranolol hydrochloride tablets. Journal of Controlled Release, 38(1), 11-20.

10. Eddington, N. D., Ashraf, M., Augsburger, L. L., Leslie, J. L., Fossler, M. J., Lesko, L. J., ... \& Rekhi, G. S. (1998). Identification of formulation and manufacturing variables that influence in vitro dissolution and in vivo bioavailability of propranolol hydrochloride tablets. Pharmaceutical development and technology, 3(4), 535-547.

11. Ghabrial, H., Nand, R., Stead, C. K., Smallwood, R. A., \& Morgan, D. J. (1994). Product inhibition and dosedependent bioavailability of propranolol in the isolated perfused rat liver preparation. Journal of pharmaceutical sciences, 83(7), 931-936. 
12. Takayama, K., \& Nagai, T. (1989). Novel computer optimization methodology for pharmaceutical formulations investigated by using sustained-release granules of indomethacin. Chemical and pharmaceutical bulletin, 37(1), 160167.

13. Garg, R. (2008). Pre-formulation: A need for dosage form design; pharmainfo.net.

14. Banker, G.S., Rhodes, C.T. (2000). Modern Pharmaceutics. $4^{\text {th }}$ ed. New York: Marcel Dekker Inc.

15. Chemsa, S. I., Maïza, A., \& Arnaud, P. (2018). Sustained-Release Tablets of Hydrochlorothiazide, a Slightly WaterSoluble Molecule Using Glyceryl Behenate. Pharmaceutical Chemistry Journal, 52(1), 15-18.

16. Rockville, M. D. (2007). United States of Pharmacopeia-National Formulary. In USP30-NF25. The United States Pharmacoepial Convention.

17. Talukdar, M. M., Michoel, A., Rombaut, P., \& Kinget, R. (1996). Comparative study on xanthan gum and hydroxypropylmethyl cellulose as matrices for controlled-release drug delivery I. Compaction and in vitro drug release behaviour. International journal of pharmaceutics, 129(1-2), 233-241.

18. Sato, H., Miyagawa, Y., Okabe, T., Miyajima, M., \& Sunada, H. (1997). Dissolution mechanism of diclofenac sodium from wax matrix granules. Journal of pharmaceutical sciences, 86(8), 929-934.

19. Möckel, J. E., \& Lippold, B. C. (1993). Zero-order drug release from hydrocolloid matrices. Pharmaceutical research, 10(7), 1066-1070.

20. Owusu, F. W., Boakye-Gyasi, M. E., Mante, P. K., Ekuadzi, E., Ofori-Kwakye, K., \& Woode, E. (2019). Formulation and evaluation of sustained release matrix tablets of capparis erythrocarpos roots extract to improve patient compliance in management of arthritis. Scientific African, 6, e00172.

21. Gao, P., Skoug, J. W., Nixon, P. R., Ju, T. R., Stemm, N. L., \& Sung, K. C. (1996). Swelling of hydroxypropyl methylcellulose matrix tablets. 2. Mechanistic study of the influence of formulation variables on matrix performance and drug release. Journal of pharmaceutical sciences, 85(7), 732-740.

CITATION: Rashmi Shivaji Tambare et al (2021). Development and in Vitro Evaluation: Once-Daily Sustained Release Matrix Tablets of Propranolol. South Asian Res J Pharm Sci, 3(2): 27-33. 